\title{
OCHO BALAY: DESIGN OF A PERMANENT TYPHOON SHELTER FOR THE RURAL AREAS IN THE PHILIPPINES
}

\author{
${ }^{1}$ Rowell Ray SHIH ${ }^{*}{ }^{2}$ Danilo RAVINA \\ ${ }^{1,2}$ Department of Architecture, School of Architecture, Fine Arts and Design \\ University of San Carlos, Cebu City, Cebu, Philippines \\ e-mail: ${ }^{1}$ drowellshih@yahoo.com, ${ }^{2}$ dravina@yahoo.com
}

Received 5 November 2019; accepted 18 January 2020

\begin{abstract}
In 2013 Typhoon Haiyan, devastated several portions of the Philippines, which resulted in more than 7,000 deaths and thousands made homeless. The aim of this study is to propose a design of a permanent shelter as a continuation of the I-Siguro Daan Transitional Shelter, which was successfully deployed in 2014 and produce a transitional shelter prototype, for the victims of typhoon Haiyan. In order to develop the methodological design of the Permanent Shelter, the author presented several factors into consideration: the understanding how the rural communities use the present I-Siguro Daan Transitional Shelter; to further develop and improve the interior space of the shelter; to propose a better roof design; and to design a sustainable toilet and kitchen area for the users. Methodologies used in the study were the use of surveys and interactions with the community, which focuses on gaining the understanding how the communities use the present I-Siguro Daan Transitional Shelter. By exploring related case studies and literatures, site surveys and consultations with different groups, the resulting Permanent Shelter will a promising solution for improving the lives of the communities while also providing groundwork for future shelter related studies.
\end{abstract}

Keywords: Permanent shelters, Emergency shelters, Post disaster housing

\section{Introduction}

The Philippines, sitting on the 'Pacific Ring of Fire', is a country that frequently faces various natural disasters [1], [2]. In 2013, typhoon Haiyan devastated the central Visayas, killing more than 7,000 people, mostly in the rural communities and

\footnotetext{
${ }^{*}$ Corresponding Author
} 
shorelines. More than 360,000 houses in Eastern Visayas were totally destroyed by Super Typhoon Haiyan, thus highlighting the importance of typhoon-resistant housing. The Philippines is a rapidly developing country, which experiences the problem of rapid family formation, poor housing and an increased scarcity of land. Housing shortage is particularly serious in the urban areas, combined with the rising cost of construction [3]. Traditional housing made from locally available materials is the only form of housing available to the poorest families and lacks any typhoon resistant features. These traditional houses can be found in the coastal and rural areas of the country and since they are weak, many of them are destroyed annually. The importance of and need for disaster resilient permanent shelters are increasing globally, as no nation is immune from the effects of natural disasters. Permanent Shelters are usually progressed from transitional shelters and from a core shelter [4]-[9]. This paper proposes to design and develop a Typhoon permanent shelter as a continuance of the previous original work of the I-Siguro Daan Transitional Shelter proposed by the authors [10]. The configuration of the I-Siguro Daan (Fig. 1) has a rectangular floor plan of $4.7 \mathrm{~m} \times 2.4 \mathrm{~m}$ with a total height of $3.5 \mathrm{~m}$, measured up to the apex of the roof. The proposed typhoon shelter must require the same or close to the minimum on-site construction activities, workers and equipment while using the available local resources. Thus, the aim of the study is to provide a transition to the permanent shelter design. In this paper, the authors conceptualize, design and develop a permanent typhoon shelter for a single family based upon the original groundwork of the I-Siguro Daan Transitional Shelter. The shelter must likewise be affordable without sacrificing the structural integrity of the project and must be culturally sensitive to the Filipino community.

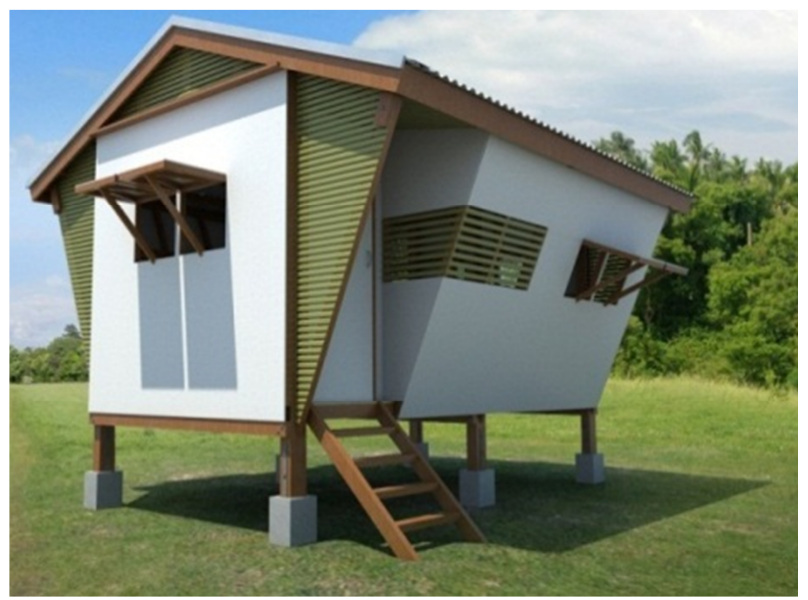

Fig. 1. Exterior of the I-Siguro Daan transitional shelter

\section{Methodology}

The process of community participation was used in the final design of the proposed permanent shelter. This is significant because the re-housing process involves major 
change and requires a profound restructuring of daily life of the community [11]. Field research, interviews and surveys were being used as one of the basis for the final of the shelter. In this methodology, the author gathered data analysis from the beneficiaries of the I-Siguro Daan Shelters, particularly from the Northern part of Cebu after typhoon Haiyan. Furthermore, field research and surveys were being done by the author from the beneficiaries of the permanent socialized housing units. The main objective of the surveys and interviews was the user satisfaction rate and use of the shelters by the beneficiaries. The results of the surveys and interviews resulted in the importance of better shelters for the Filipino. Data also showed that the average number of families that occupy these units' number to five, which includes the children and in some cases, the extended family members. These family members are contented with the 28 square meters provided by each housing unit, although most of the users would want to socialize with their friends and neighbors outside their home. The need to socialize and interact with different friends and family members is a trait that most of the Filipino family adheres to. There is a need to also have a large open space for other extracurricular activities that may involve other members of the family. The family members also find the need to make their own small store business. Majority of the beneficiaries also raised poultry and livestock. Although these animals are being regulated by the members of the community, they are very useful especially when families have a hard time buying their own food. The findings of the survey resulted in the following concerns by the beneficiaries:

i) Need for more open spaces;

ii) Flood prevention system;

iii) Spaces for poultry and plants;

iv) Affordable housing;

v) Improved indoor ventilation;

vi) Expandable indoor space; and

vii) Capacity to develop the shelter when their financial status improves over time.

The results of these surveys will therefore be one of the design considerations of the proposed typhoon shelter that is presented in this study.

\section{Design of the Ocho Balay}

In this study, the authors present the Ocho Balay, which means 8 Houses. The name of the shelter is based on the plan and the design of eight sided walls, which the shelter is known for. The proposed unit was also designed after an extensive analysis of local architecture while respecting the local traditions and culture so as to enhance the feasibility of replication and maintenance of the shelters by the beneficiaries. Thus, easy accessibility and economic materials are an important factor when constructing permanent structures [12]. It is therefore important to analyze the context of the location of the shelters. The shelter design must be flexible enough on the use of local construction materials and allow replacement with alternatives. The basic materials used in the shelter are: 
1) Coco Lumber;

2) Amakan and

3) Bamboo Splits.

For the exterior framing, Coco Lumber was used because it is a common hardwood substitute from the coconut palm trees found in the Philippines (Fig. 1). However, 4 " 4 " for post may be difficult to come by, so the basic dimension to be used shall be 2 "x4" and 2"x6" with lengths at 8' and 10".

As for the walls, Amakan offers a cheap yet durable alternative. The use of concrete board and plywood can also be used in the future when the families are able to upgrade their economic status. Simplicity in design was an important design consideration because simple shelters for the commons are much easier to communicate. The shelter has fewer moving parts, fewer interactions, and fewer opportunities for failure. Strengthening individual identity and sense of community was also a design consideration. The shelter design was based on the popular traditional Filipino House, the Bahay Kubo. It employs passive cooling principles and has ample natural light during the day. Furthermore, the United Architects of the Philippines recommends a four sided hip roof (Fig. 2) because it is more streamlined and sealed against buffeting winds. Thus, use of four sided roofs was being proposed in this design.

The design of the shelter also allows for incremental development. The concept of incremental housing is based on the capacity to adapt the house model to the development of the family [13]. The indication of incremental development is typically associated with developing countries, where access to institutional housing finance is limited or unavailable, particularly for low-income households. The main structural characteristics of the proposed shelter is the use of the Bent Structure which is a transverse rigid frame similar to that of the three-hinged arches [14], [15], [16]. The Bent Structure structural system is, made of coco lumber (Fig. 3), which resulted in slanted walls on the exterior.

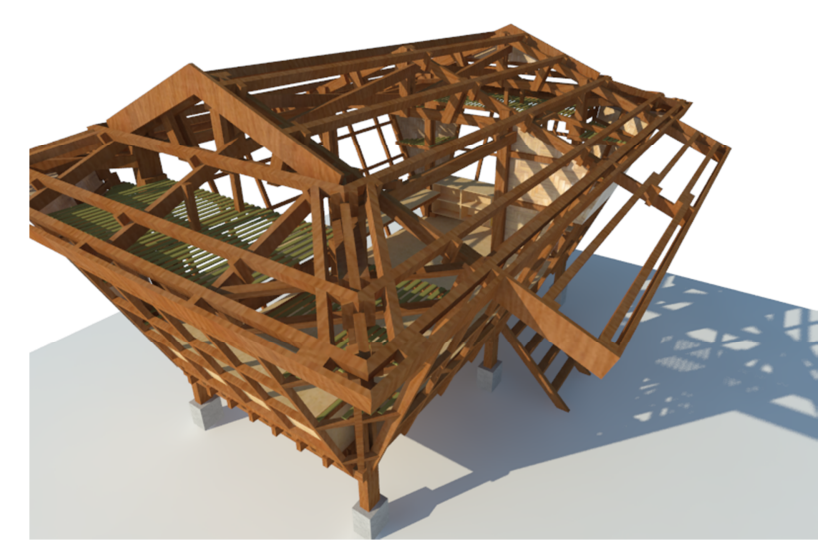

Fig. 2. Coco Lumber exterior framing 


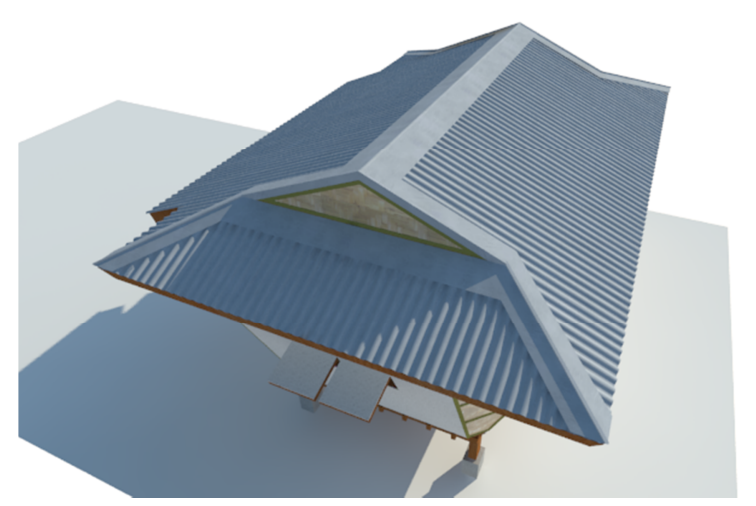

Fig. 3. Proposed four sided hip roof

The slanted walls (Fig. 4, Fig. 5) will make the interior appear larger while providing more storage. The sides can also be safely extendable in all directions when the families improve their financial status in the future. This can also be seen as a strategy for continuous growth and improvement. Work or improvements done on one side can be easily upgraded on the other side in a more permanent way with a more resistant material.

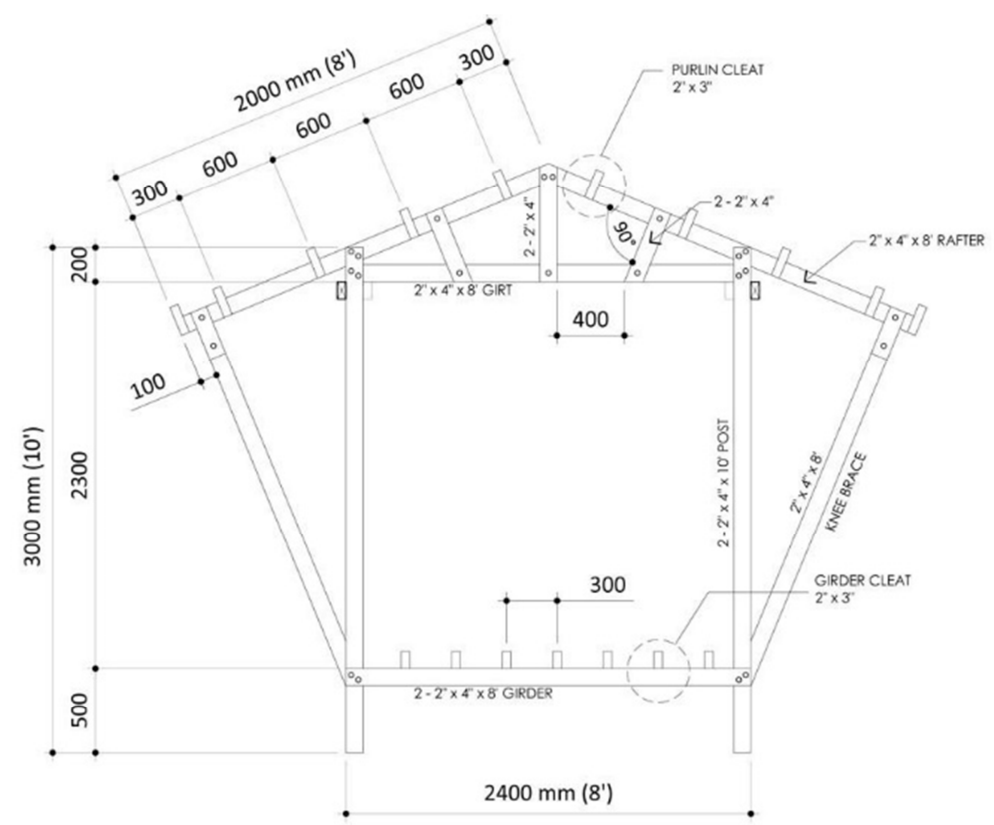

Fig. 4. Detail of the Bent Structure 


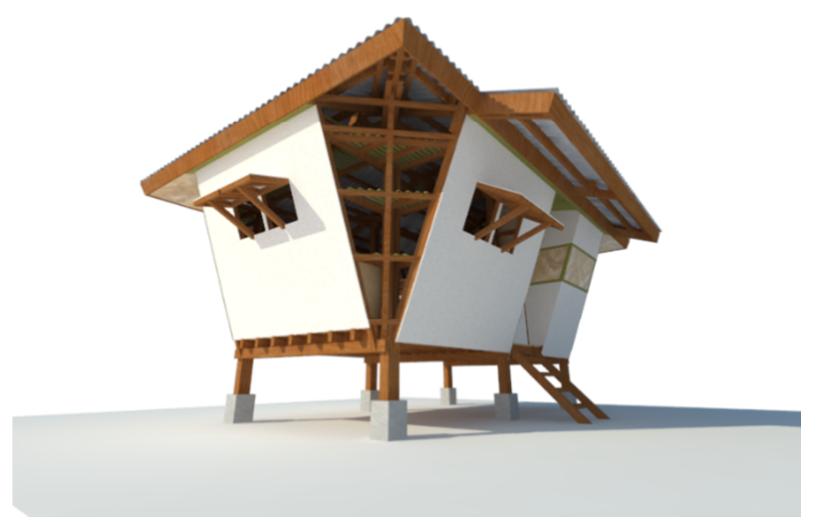

Fig. 5. The slanted walls of the shelter and corner wall (exposed)

The spaces of the interior of the shelter are divided into two parts:

1) Living Module; and the

2) Sleeping Module.

For Filipinos, these spaces encourage communal activity, which allows social gatherings and activities [17]. As it can be seen in the plan, the walls are constructed of breathable materials for better thermal comfort and allow views from the inside to the outside while allowing natural cross ventilation (Fig. 6).

In order to allow cross ventilation and thermal comfort during the day, the elevated floor is made up of fiber cement boards or bamboo stripes. Lockable windows made of wooden shutters enhance the cross ventilation and thermal comfort while fascia boards and short overhangs of the roof minimize the negative forces on the roof during a typhoon. The roof is made up of GI Corrugated sheets on coco purlins and reinforced with the traditional umbrella nails, which can help in securing the roof during a strong typhoon. The height of the floor level is $900 \mathrm{~mm}$ but nevertheless can be adjusted according to the site location (Fig. 7 and Fig. 8). Depending on the site location and potential hazards of the area, the height of the post can be adjusted, especially in flood prone areas.

In terms of added function, the author proposed an outdoor toilet and kitchen. The outdoor toilet and kitchen are designed with a reinforced concrete frame combined with reinforced concrete slab, forming a safe box for occupants to shelter in case of extreme typhoon. The slanted roof encourages rainwater harvesting for the families. Rainwater can be collected for toilet use and/or for urban gardening systems. Rooftop rainwater harvesting is the most common technique of rainwater harvesting for domestic consumption. In rural areas, this is most often done at small-scale. Rainwater harvesting can supplement water sources when they become scarce or are of low quality like brackish groundwater or polluted surface water in the rainy season. This is simple, lowcost technique that requires minimum specific expertise or knowledge and offers many 
benefits. Rainwater is collected on the roof and transported with gutters to a storage reservoir, where it provides water at the point of consumption for the families. In this design, the author proposed a rainwater harvesting system with the use of a simple PVC container which is popular in the Philippines (Fig. 9).

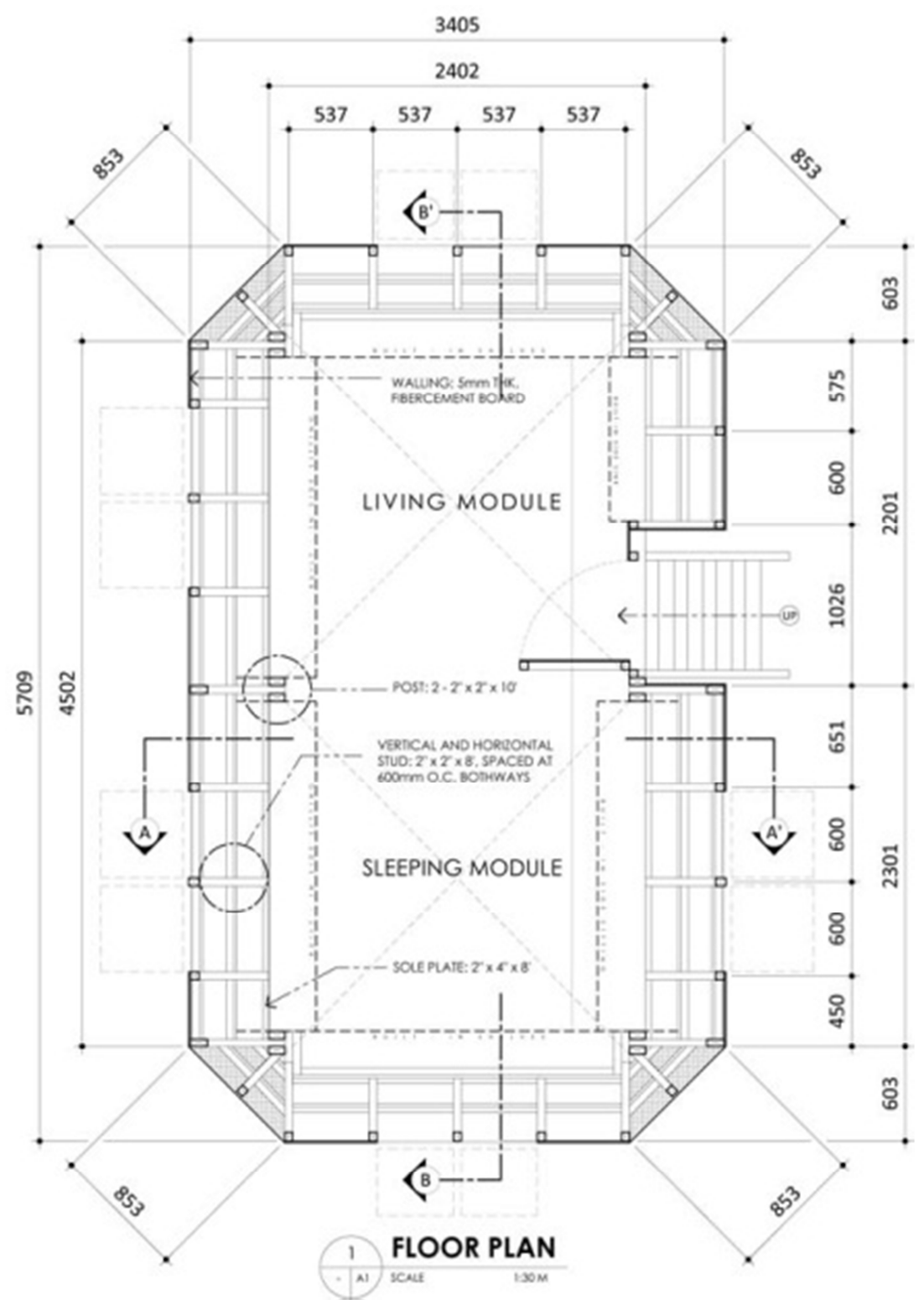

Fig. 6. The living and sleeping module of the interior 


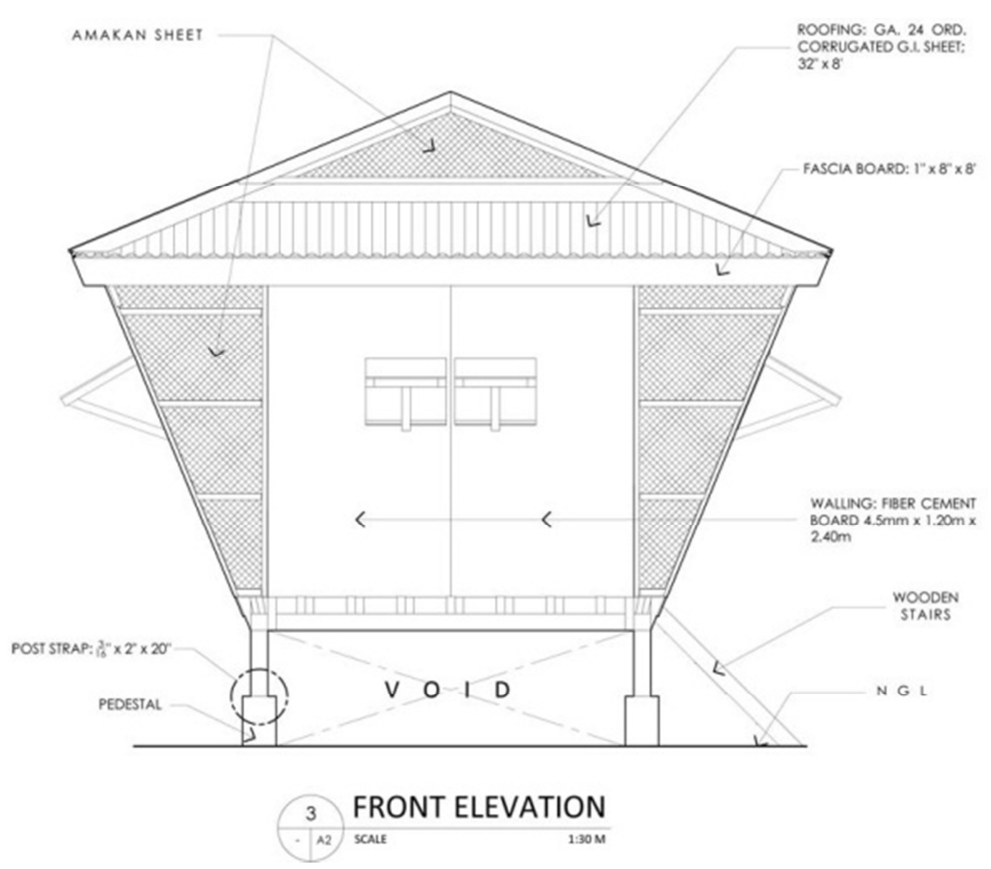

Fig. 7. Front elevation

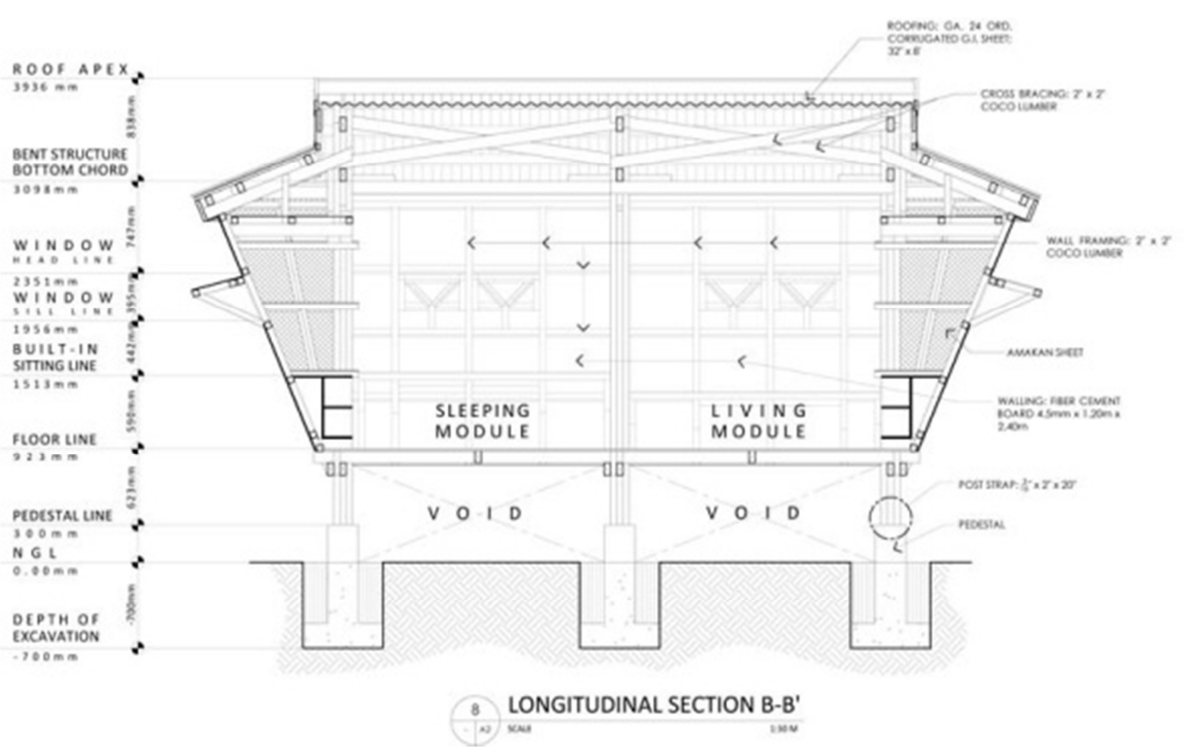

Fig. 8. Longitudinal section

Pollack Periodica 15, 2020, 2 


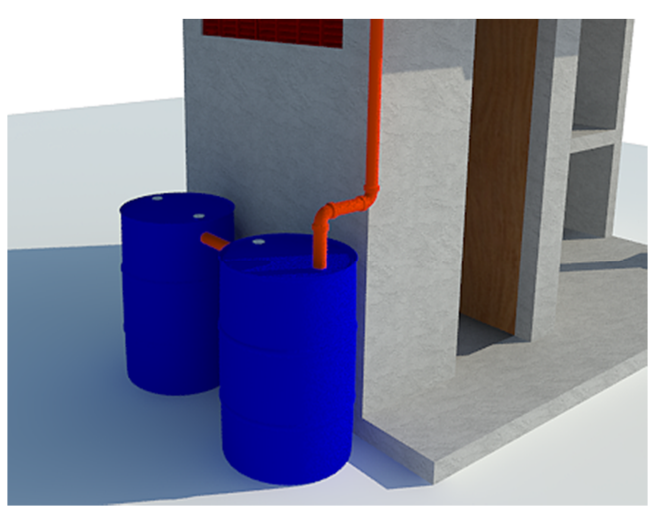

Fig. 9. A simple PVC container for rainwater harvesting

Rainwater are collected in the gutter of the roof and then channeled down via pipes to a plastic water container tank near the comfort room. Finally, as seen in the plans (Fig. 10 and Fig. 11) building the toilet and kitchen with hollow blocks and reinforced concrete will also provide opportunity to incorporate training program for masons and thus improve the construction quality in the foreseeable future. Fig. 12 shows the proposed exterior of the toilet and kitchen.

A scale model (Fig. 13) shows how the interior and exterior framings will be built. In terms of cost, the estimated budget for each unit is US\$ 1, 904.66 as of January 8, 2019 with a floor area of 19 square meters for a family of five. Making each unit affordable will obviously allow for more housing unit to be built and therefore will result in more beneficiaries having a shelter of their own.

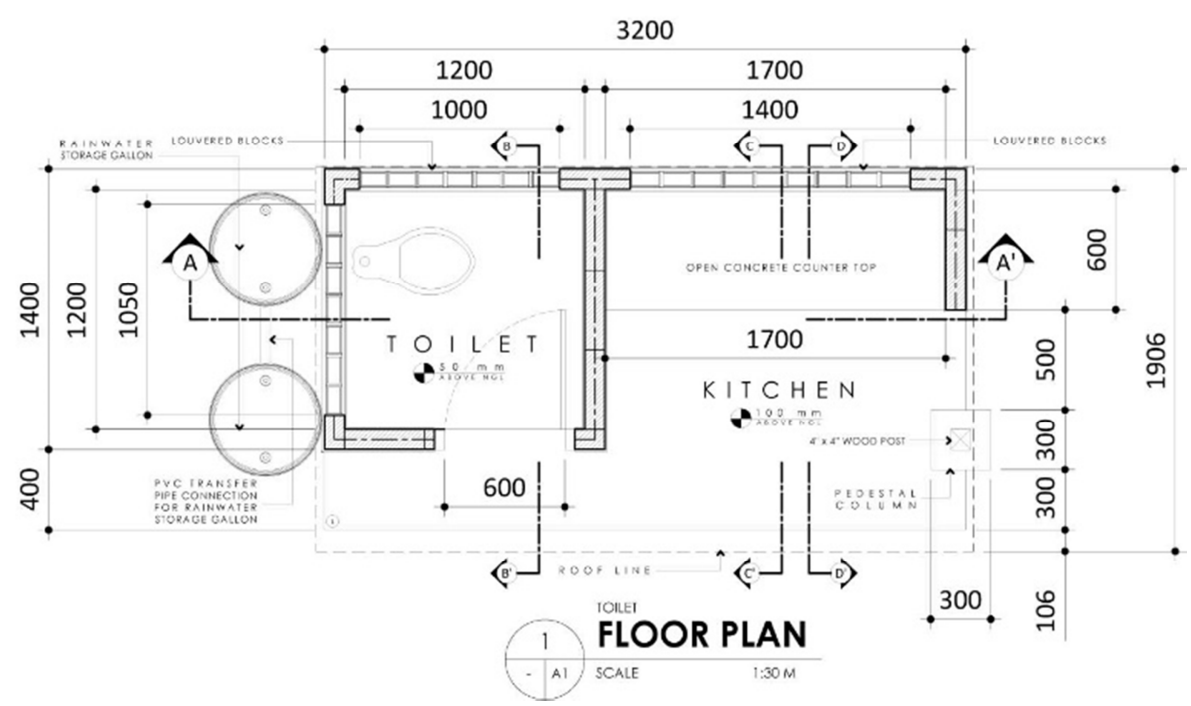

Fig. 10. Floor plan of the toilet and kitchen 


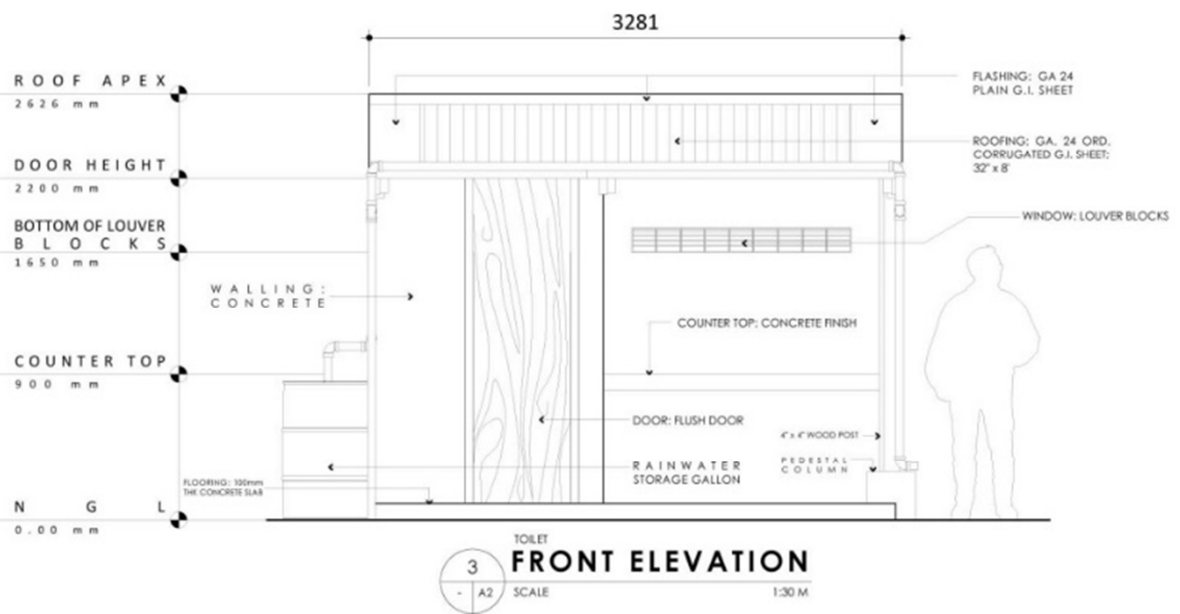

Fig. 11. Front elevation of the toilet and kitchen

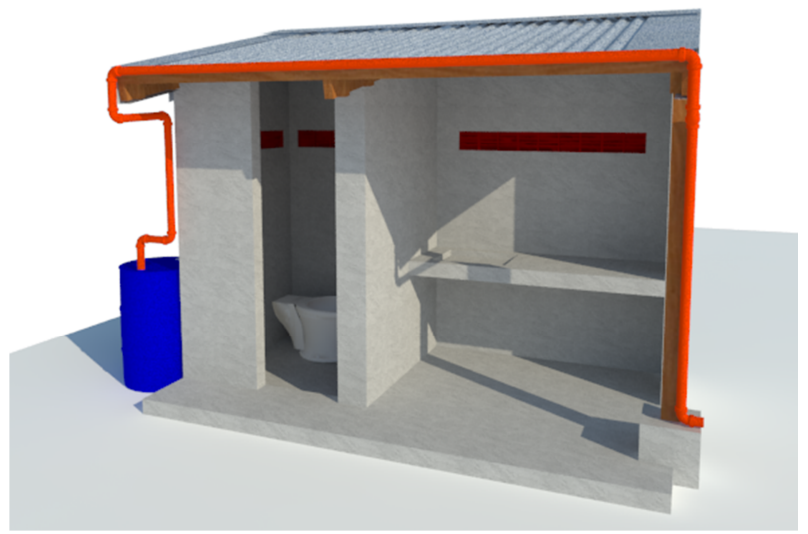

Fig. 12. Exterior perspective of the toilet and kitchen

\section{Conclusion}

Natural disasters continue to leave thousands of Filipino people homeless every year, forcing them to seek refuge without any other alternatives. On many occasions, the local government cannot cope with the affected families and therefore limiting their resources. This study proposes a permanent typhoon shelter that is affordable and yet can be easily upgraded. The main structural material used in the shelter is Coco Lumber, which is very abundant in the Philippines. The proposed unit has a simple rectangular building form with a hip roof for easy construction by the local workers. The short 
overhang design can effectively reduce the impacts of wind force that is the main cause of damage to the roof structure during a typhoon.

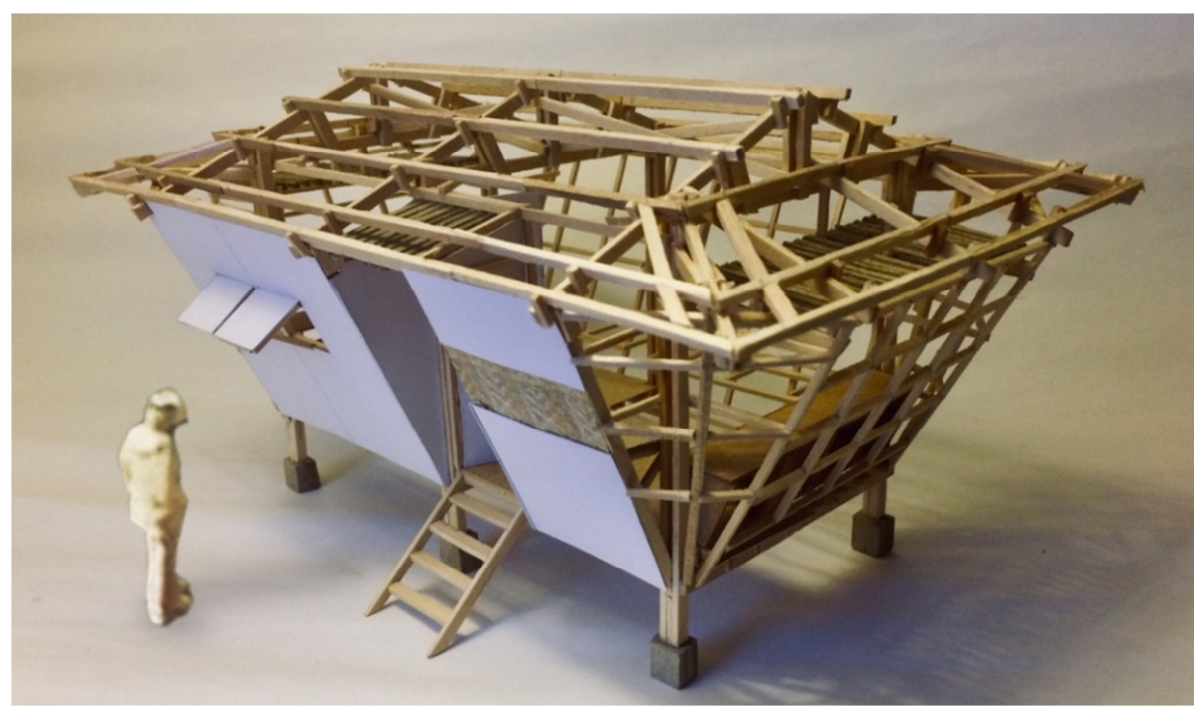

Fig. 13. Study Scale Model showing the interior and exterior framings.

The author likewise recognizes the importance of the Slanted Wall Design, as applied to the I-Siguro Daan Shelter series. The slanted walls will make the interior appear larger while providing more storage. The unusable space where the walls meet the floor can be turned into storage spaces. The house can also be expanded horizontally to have more spaces if the need arises. The slanted roof encourages rainwater harvesting for the families. Rainwater can be collected for toilet use and/or for urban gardening systems. Building the toilet and kitchen with hollow blocks and reinforced concrete will also provide job opportunities to the community. Finally, the shelter also offers a flexible solution, which at the same time is moderate in cost. This shelter will hopefully be a stepping stone on the journey towards a brighter future for the beneficiaries in the Filipino's pursuit of a better quality of life, especially after the traumatizing effects of a natural disaster. As architects and designers, the application of innovation and creativity plays an important role in the construction practices, which results in an efficient methodology that can be replicated after natural disasters.

\section{Acknowledgements}

This work has been undertaken as part of a community project by the University of San Carlos School of Architecture, Fine Arts, Republic of the Philippines and Design and Marcel Breuer Doctoral School, Faculty of Engineering and Information Technology, University of Pecs, Hungary. 


\section{References}

[1] Van Voorst R., Wisner B., Hellman J.,Nooteboom G. Introduction to the 'risky everyday', Disaster Prevention and Management, Vol. 24, No, 4, 2015, pages 1-6.

[2] Wisner B., Blaikie P., CannonT., Davis J. At risk: natural hazards, people's vulnerability and disasters, Routledge, 2005.

[3] Diacon D. Typhoon resistant housing in the Philippines: The core shelter project, Disasters, Vol. 16, No. 3, 1992, pp. 266-271.

[4] Quarantelli E. L. Patterns of sheltering and housing in US disasters, Disaster Prevention and Managemen, Vol. 4, No. 3, 1995, pp. 43-53.

[5] Wu J. Y., Lindell M. K. Housing reconstruction after two major earthquakes: The 1994 Northridge earthquake in the United States and the 1999 Chi-Chi earthquake in Taiwan, Disasters, Vol. 28, No. 1, 2004, pp. 63-81.

[6] Johnson C., Lizarralde G., Davidson C. H. A systems view of temporary housing projects in post-disaster reconstruction, Construction Management and Economics, Vol. 24, No. 4, 2006, pp. 367--378.

[7] Johnson C. Impacts of prefabricated temporary housing after disasters: 1999 earthquakes in Turkey, Habitat International, Vol. 31, No. 1, 2007, pp. 36-52.

[8] Johnson C. Strategic planning for post-disaster temporary housing, Disasters, Vol. 31, No. 4, 2007, pp. 435-458.

[9] Félix D., Branco J. M., Feio A. Temporary housing after disasters: A state of the art survey, Habitat International, Vol. 40, 2013, pp. 136-141.

[10] Ravina D., Shih R. R. A shelter for the victims of the Typhoon Haiyan in the Philippines: The design and methodology of construction, Pollack Periodica, Vol. 12, No. 2, 2017, pp. 129-139.

[11] Davidson C. H., Johnson C., Lizarralde G., Dikmen N., Sliwinski A. Truths and myths about community participation in post-disaster housing projects, Habitat International, Vol. 31, No. 1, 2007, pp. 100-115.

[12] Ohlson S., Melich R. Designing and developing sustainable housing for refugee and disaster communities, IEEE Global Humanitarian Technology Conference, San Jose, CA, USA, 10-13 October 2014, pp. 614-619.

[13] Greene M., Rojas E. Incremental construction: a strategy to facilitate access to housing, Environment and Urbanization, Vol. 20, No. 1, 2008, pp. 89-108.

[14] Benson T. Building the timber frame house: The revival of a forgotten craft, Simon and Schuster, 1981.

[15] Bosher L., Dainty A. Disaster risk reduction and 'built-in 'resilience: towards overarching principles for construction practice, Disasters, Vol. 35, No. 1, 2011, pp. 1-18.

[16] Faherty K. F., Williamson T. G. Wood engineering and construction handbook, McGrawHill, 1998.

[17] Ravina D. V., Shih R. R. L., Medvegy G. Community architecture: the use of participatory design in the development of a community housing project in the Philippines, Pollack Periodica, Vol. 13, No. .2, 2018, pp. 207-218. 